\title{
The Effect of DC Plating Parameters on the Composition and Morphology of Silver-copper Alloy
}

\author{
C.Shanthi (Corresponding author) \\ Department of Physics \\ Sona College of Technology \\ Salem 636005, Tamilnadu, India
}

Tel: 91-427-409-9791 E-mail: shanthi_rec@yahoo.co.in

\author{
S.Barathan \\ Department of Physics \\ Annamalai University \\ Annamalai nagar-608002, Tamilnadu, India \\ Tel: 91-414-422-2751 E-mail: sbarathan_au@rediffmail.com \\ RajasrisenJaiswal \\ Department of Physics \\ Sona College of Technology \\ Salem-636005, Tamilnadu, India \\ Tel: 91-427-409-9823 E-mail: senoritta_in@yahoo.co.in
}

\section{R.M. Arunachalam}

Department of Mechanical Engineering,

Sona College of Technology

Salem-636005, Tamilnadu, India

Tel: 91-427-409-9716 E-mail: arun_rm@yahoo.com

The research is financed by All India Council for Technical Education (AICTE), New Delhi under the Research Promotion Scheme File No. 8023/BOR/RPS-145 /2006-07 and Sona College of Technology.

\begin{abstract}
This research attempts to optimize the parameters for DC plating of silver on silver alloy of two different compositions namely $50 \%$ and $75 \%$ silver alloy. In the Silver -copper alloy, the surface morphology and composition of the electro deposit are influenced by current density, silver concentration in the bath, applied current type and addition of additive. It has been found that concentration of silver in silver alloy has an effect in weight
\end{abstract}


electrodeposited over cathode in DC plating. The surface morphology is studied by taking SEM micrograph for the two different compositions of silver alloy and grain size is measured using XRD analysis. Higher the purity of silver, finer is the grain size. It has been observed that with the increase of silver in the sample, the amount of silver deposited, hence the thickness of the deposit varies for the same current and voltage settings.

Keywords: DC plating, Silver alloy, Current density, Thickness

\section{Introduction}

Electroplated silver was developed primarily for use on hollowware, flatware and tableware. It has proven its usefulness in both decorative and functional applications in both Engineering, electrical and electronic applications. Its great success has been virtually a complete replacement of gold on metallic lead frames, the devices that support majority of silicon chips. Silver has been used as a bearing surface for many decades. Silver is plated almost exclusively with cyanide based solutions, despite the considerable research effort that has been expended on evaluating less toxic alternatives. It is possible to produce fully bright deposits that require no further buffing or polishing. This is achieved by including a brightening agent in the solution formula (Sarkar, 1971).Silver holds a distinguished position among the metals as it was the first metal covered by a patent for electroplating (Orr, 1982). Copper is the only metal with which silver forms a simple eutectic between two well defined terminal solid solutions. The salient feature of this system is that useful alloys are found over the full range of composition. The fact that the eutectic is between two terminal solid solutions, each having very similar properties, is largely responsible for this. The silver copper eutectic is the basis for the large family of silver -copper-zinc and silver copper zinc cadmium industrial brazing alloys. This alloy has the best combination of strength, hardness and electrical properties of any of the silver alloys. Numerous silver copper alloys in the range 99.8 percent silver down to 50 percent have been used for electric contacts, brazing and silver jewellery industry (McDonald, 1982).This research attempts to optimize the parameters for DC plating of silver over silver alloy for two different compositions namely $75 \%$ silver, $25 \%$ copper and $50 \%$ silver and $50 \%$ copper. DC plating is the process of depositing a coating having a desirable form by means of electrolysis. The main purpose is to alter the characteristics of a surface so as to provide improved appearance, ability to withstand corrosive agents, resistance to abrasion or other desired properties or a combination of them (Nasser Kanani, 2004).But with the advent of pulse plating, which is defined as metal deposition by pulsed electrolysis (interrupted direct current to electroplate parts) the above said properties are improved (Knodler, A., 1986).Pulse plating leads to smoother and fine grained deposits (Shanthi, et al.,2008) and almost completely free of pinholes. Pulse plating also reduces the variation of plating thickness from one part to the next. Plating speeds can be increased. Current efficiency is improved and raw material consumption is also low. Our present investigation is to optimize the parameters for DC plating of silver on silver alloy of two different compositions namely $50 \%$ and $75 \%$ silver alloy.

\section{Experimental}

\subsection{Bath composition}

Potassium cyanide, Silver Potassium cyanide and Commercial Brightener are the main composition of the bath with a silver content of 30gms/litre (Canning, W., 2005). The purity of the anode silver is $99.99 \%$.Anode and cathode size ratio should be 2:1. Silver metal concentration is normally maintained by anode dissolution which needs small additions of metal salt occasionally. This is processed further by adding either silver cyanide or potassium silver cyanide. Silver is present as potassium silver cyanide, and its concentration must be maintained by making periodic additions of this double salt. Buffer salt is added to maintain the $\mathrm{pH}$ level.

\subsection{Specimen Preparation}

Samples from two different silver compositions namely $50 \%$ and $75 \%$ silver alloy are prepared by melting 50 grams of pure silver and $50 \mathrm{grams}$ of copper and $75 \mathrm{grams}$ of pure silver and $25 \mathrm{grams}$ of copper at a temperature of $1100^{\circ} \mathrm{C}$ in a crucible using a charcoal furnace respectively. The molten silver ingot is poured in a rectangular casting plate of length $3 \mathrm{~cm}$ and height $0.7 \mathrm{~cm}$ and cooled at room temperature. This ingot is pressed and rolled in a press roller to get $0.17 \mathrm{~cm}$ thickness sheet. Then it is cut into a size of $7 \mathrm{cmX} 2.5 \mathrm{~cm}$. Surface of the specimen was cleaned with acid pickling and polished in a vibrator polisher and finally hand brushed and cleaned with tap water. 


\subsection{Procedure of conducting the experiment}

The anode which is annealed pure silver $(99.99 \%)$ is connected to the positive terminal of the rectifier and the specimen cathode is connected to the negative terminal of the rectifier. A filter unit is used to remove the impurities in bath continuously. Deposition of silver is on the cathode silver alloy which undergoes a displacement of $8.75 \mathrm{~cm} / \mathrm{second}$ to avoid polarization in the solution. DC plating is studied for the peak current densities of $3.2103 \mathrm{~A} / \mathrm{dm}^{2}, 3.7453 \mathrm{~A} / \mathrm{dm}^{2}$ and $4.5479 \mathrm{~A} / \mathrm{dm}^{2}$ by giving a value to ON time and making the OFF time zero in the pulse rectifier. A DC voltage of 1.2volt and DC current of 1.2, 1.4 and 1.7 amp are set up and plating is done for 60 seconds with suitable bath composition. The cathode is weighed before and after electroplating and theoretical, experimental thickness, current efficiency are calculated and hardness measured using microhardness tester are recorded as shown in the Table 1.

\section{Results and discussion}

Samples from two different silver compositions namely $50 \%$ and $75 \%$ silver alloy have been made and electrodeposited. Figure 1 shows the SEM micrograph for DC plating of $75 \%$ silver and $25 \%$ copper alloy for a peak current density of $3.7453 \mathrm{~A} / \mathrm{dm}^{2}$ and figure 2 shows the SEM micrograph for DC plating of $50 \%$ Silver and $50 \%$ Copper alloy for the same peak current density of $3.7453 \mathrm{~A} / \mathrm{dm}^{2}$. In the Silver -copper alloy, the surface morphology and composition of the electro deposit are influenced by current density, silver concentration in the bath, applied current type and addition of additive ( Mohan, et al.,2005). The increase of current density has increased the amount of weight electrodeposited and hence the thickness of the silver deposit. Experimentally it is determined that the current density for minimum time and maximum deposition as $3.7453 \mathrm{~A} / \mathrm{dm}^{2}$ for $50 \%$ silver alloy and $4.5479 \mathrm{~A} / \mathrm{dm}^{2}$ for $75 \%$ silver alloy for a specimen size of $0.7 \mathrm{dm}$ x $0.25 \mathrm{dm}$ beyond which darkening of the specimen is observed. Burning deposit is found in $50 \%$ silver alloy for a peak current density of $4.5479 \mathrm{~A} / \mathrm{dm}^{2}$ and the hardness is found to be maximum. The current efficiency is found to be maximum for a current density of $3.7453 \mathrm{~A} / \mathrm{dm}^{2}$ for $50 \%$ silver alloy and $75 \%$ silver alloy. It is found that concentration of silver in silver alloy has an effect in the weight electrodeposited over cathode in DC plating. Pure silver has low resistance, high current flow and so conductivity is more. It has been observed that with the increase of silver in the sample, the amount of silver deposited, hence the thickness of the deposit varies for the same current and voltage settings. Hence more amount of silver has been electrodeposited for $50 \%$ silver compared to $75 \%$ silver. But for $50 \%$ silver, at a current density of $4.5479 \mathrm{amp} / \mathrm{dm}^{2}$, the current efficiency decreases to a large extent due to the formation of burnt deposit on the specimen and the hardness also increased. The deposits are not smooth and it is coarse grained in DC plating. Plating thickness varies from one part to the next. Plating speed is less and current efficiency is also less. Raw material consumption is high (Shanthi, et al., 2007).

\subsection{Grain size measurement using XRD}

Figure 3 shows the XRD pattern for 75\% Silver and 25\% Copper and Figure 4 shows the XRD pattern for 50\% Silver and $50 \%$ Copper. The grain size is calculated using Debye Scherer equation. It is observed that the grain size is finer for $75 \%$ Silver than that for $50 \%$ silver. The concentration of silver in silver alloy plays a vital role in determining the grain size. Higher the purity of silver, finer is the grain size.

\section{Conclusion}

Based on the conducted studies on DC plating of silver on silver alloy of two different compositions namely $75 \%$ silver, $25 \%$ copper and 50\% silver, $50 \%$ copper, it has been found that the concentration of silver in the cathode plays a role in deciding the amount of silver deposited on the cathode. It has been observed that with the increase of silver in the sample, the amount of silver deposited, hence the thickness of the deposit varies for the same current and voltage settings. Higher the purity of silver, finer will be the grain size. Current density above $3.7453 \mathrm{~A} / \mathrm{dm}^{2}$ for $50 \%$ silver alloy and $4.5479 \mathrm{~A} / \mathrm{dm}^{2}$ for $75 \%$ silver alloy leads to darkening of the deposits. The $75 \%$ silver alloy can withstand more current density than $50 \%$ silver alloy. For $50 \%$ silver, at a current density of $4.5479 \mathrm{amp} / \mathrm{dm}^{2}$, the current efficiency decreases to a large extent due to the formation of burnt deposit on the specimen and the hardness also increased. It is suggested that the properties are improved if the concentration of silver in silver copper alloy is more. 


\section{References}

Canning, W. (2005). The Canning handbook surface finishing technology. (23rd ed.). New Delhi: CBS publishers and distributors, (Chapter 19).

Knodler, A. (1986). Pulsed electrodeposition of precious metals. In Jean-Claude, Puippe, \& Frank Leaman (Eds.), Theory and practice of pulse plating. Florida: American electroplaters and surface finishers society, pp.164-174.

Mcdonald, A.S., Price, B.R. \& Sistare, G.H. (1982).Alloying behavior of silver and its principal binary alloys. In Allison Butts, \& Charles D. Coxe (Eds.), Silver economics, metallurgy and use. Florida: Robert Krieger Publishing Company, pp.248-254.

Mohan, S., \& Raj, V. (2005). The effect of additives on the pulsed electrodeposition of copper. Transactions of Institute of metal finishing, 83,194-198.

Nasser Kanani, (2004). Electroplating-Basic Principles: Processes and practice. Berlin, Germany: Elsevier Ltd, (Chapter 4).

Orr, M.A. (1982). Electroplating. In Allison Butts, Charles D. Coxe (Eds.), Silver economics, metallurgy and use (pp.180-189). Florida: Robert Krieger Publishing Company.

Sarkar, S. (1971). Silver the Science and Technology. Calcutta: Calcutta Book house, (Chapter 4).

Shanthi, C., Arunachalam, R.M., \& Barathan S. (2007). Study of Surface Morphology in DC plating of Silver for the Jewellery Industry, paper presented at National Conference on Advances in Surface and Interface Analysis, Salem, India.

Shanthi, C., Barathan, S., RajasrisenJaiswal, Arunachalam, R.M., \& Mohan, S. (2008).The effect of pulse parameters in electrodeposition of silver alloy. Materials letters, 62, 4519-4521.

Table 1. DC plating parameters for $75 \%$ and $50 \%$ silver alloy.

\begin{tabular}{|c|c|c|c|c|c|c|c|c|}
\hline of & $\mathrm{DC}$ & Current & Theoretical & Theoretical & Experimental & Weight & Current & Hardness \\
\hline \multirow[t]{3}{*}{ Silver } & Current & density & weight & Thickness & Thickness & Electrodeposited & Efficiency & VPN \\
\hline & Ampere & $\mathrm{A} / \mathrm{dm}^{2}$ & grams & micrometer & micrometer & grams & $\%$ & \\
\hline & 1.2 & 3.2103 & 0.0805 & 2.1427 & 1.7302 & 0.065 & 80.75 & 80.3 \\
\hline \multirow[t]{3}{*}{$75 \%$} & 1.4 & 3.7453 & 0.0939 & 2.4995 & 2.1828 & 0.082 & 87.33 & 82.4 \\
\hline & 1.7 & 4.5479 & 0.114 & 3.0355 & 2.5821 & 0.097 & 85.09 & 86.7 \\
\hline & 1.2 & 3.2103 & 0.0805 & 2.2323 & 2.0243 & 0.073 & 90.68 & 88.3 \\
\hline \multirow[t]{2}{*}{$50 \%$} & 1.4 & 3.7453 & 0.0939 & 2.6039 & 2.5234 & 0.091 & 96.91 & 81.7 \\
\hline & 1.7 & 4.5479 & 0.114 & 3.1612 & 2.5511 & 0.092 & 80.70 & 102 \\
\hline
\end{tabular}




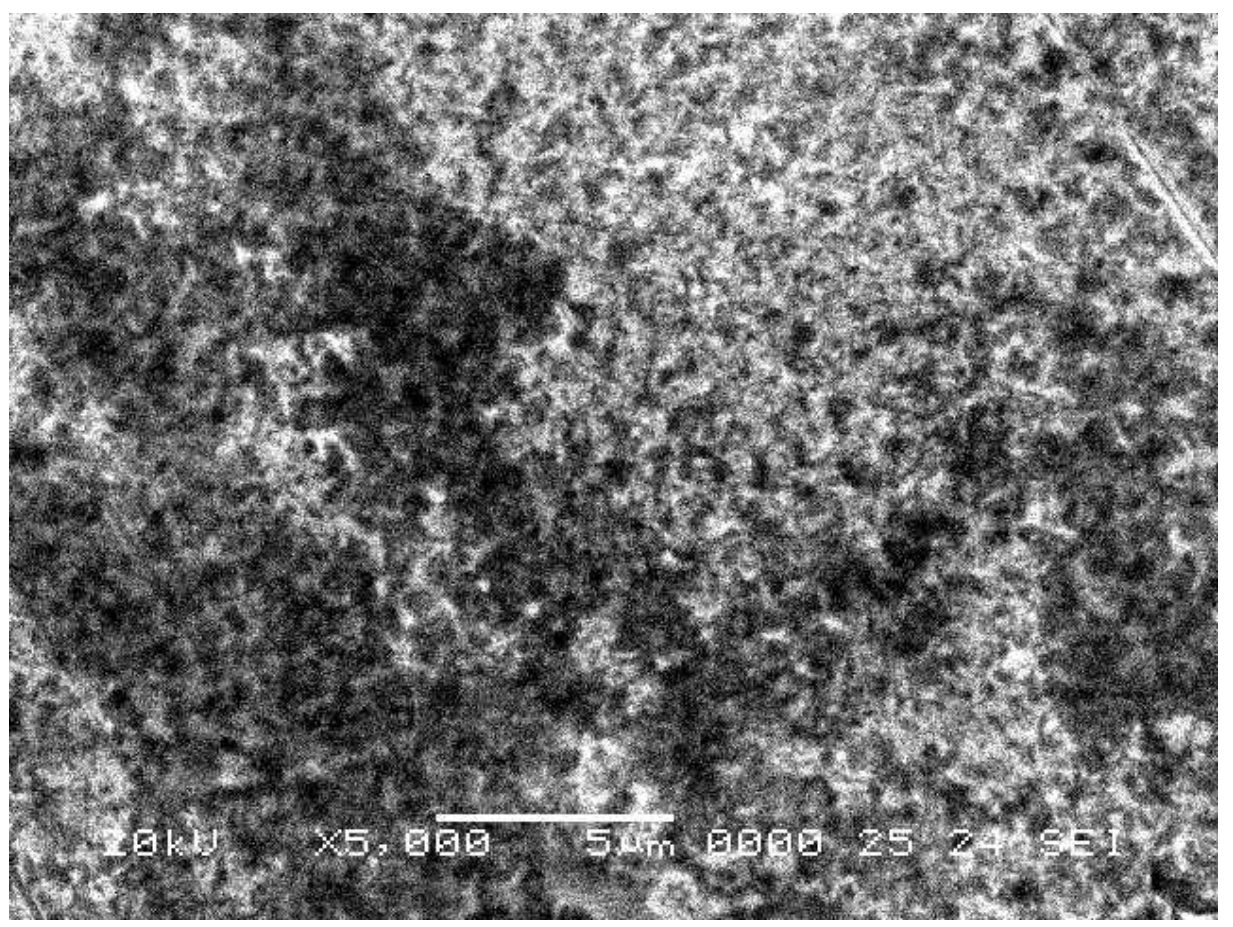

Figure 1. SEM micrograph for DC plating of $75 \%$ silver and $25 \%$ copper alloy for a peak current density of $3.7453 \mathrm{~A} / \mathrm{dm}^{2}$

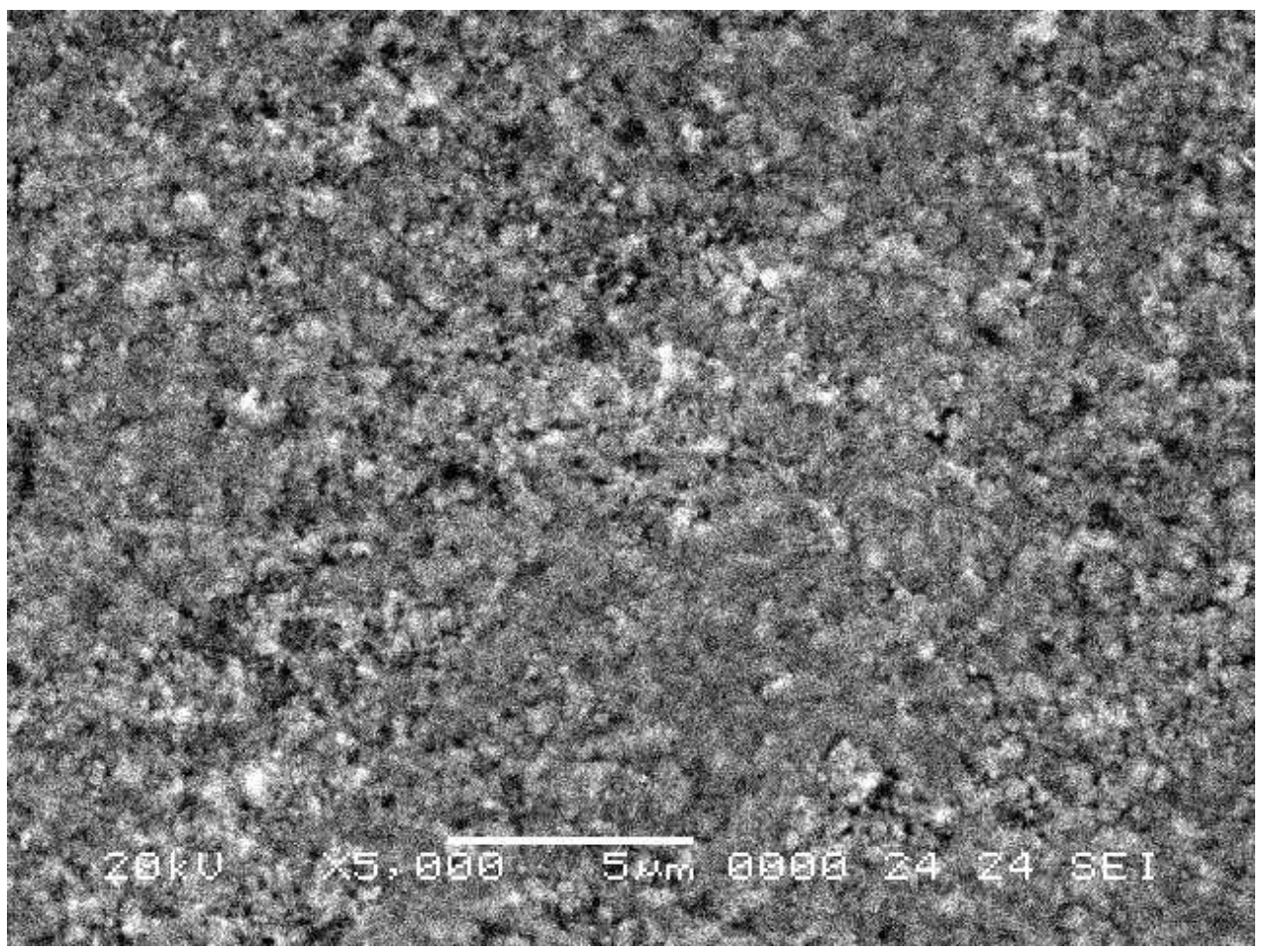

Figure 2. SEM micrograph for DC plating of 50\% Silver and 50\% Copper alloy for a peak current density of $3.7453 \mathrm{~A} / \mathrm{dm}^{2}$ 


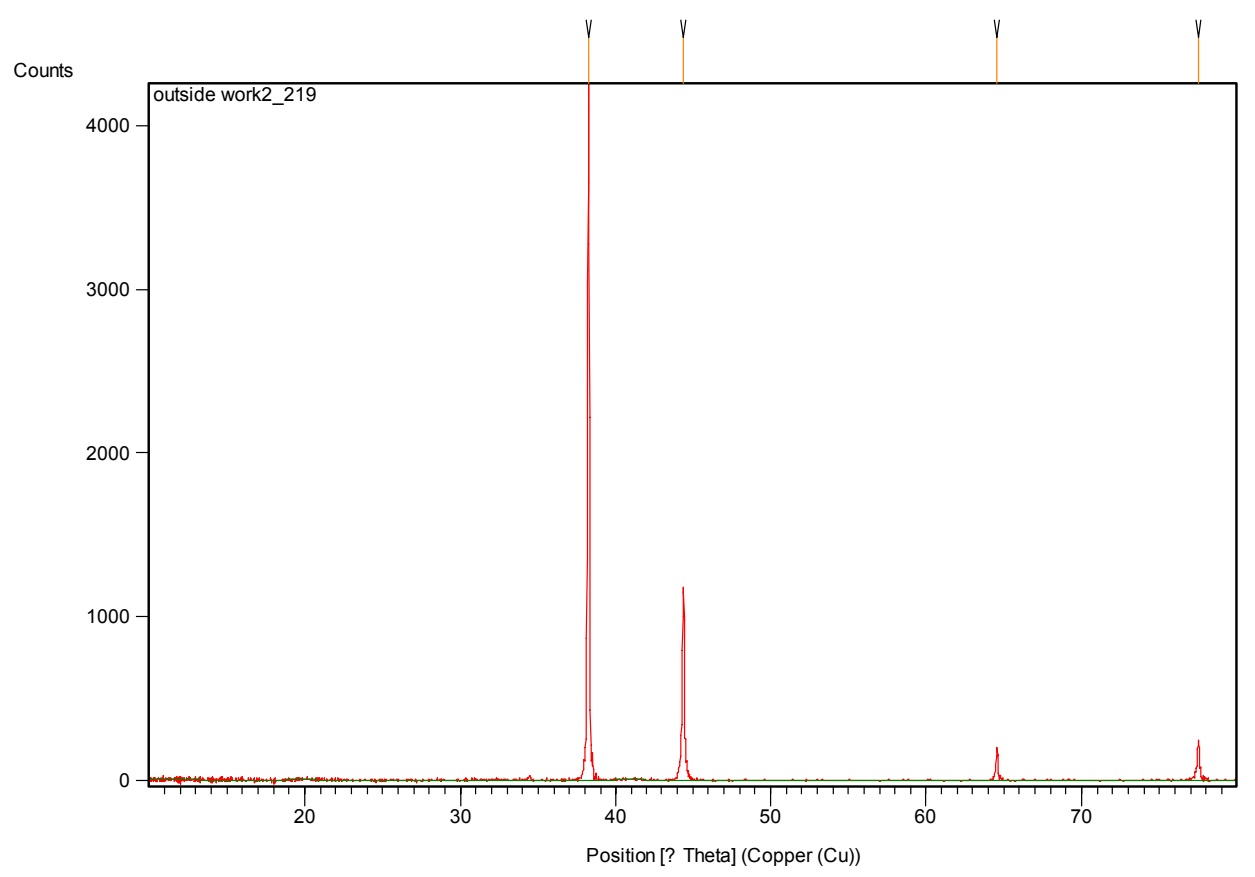

Figure 3. XRD pattern for $75 \%$ Silver and $25 \%$ Copper alloy for a peak current density of $3.7453 \mathrm{~A} / \mathrm{dm}^{2}$

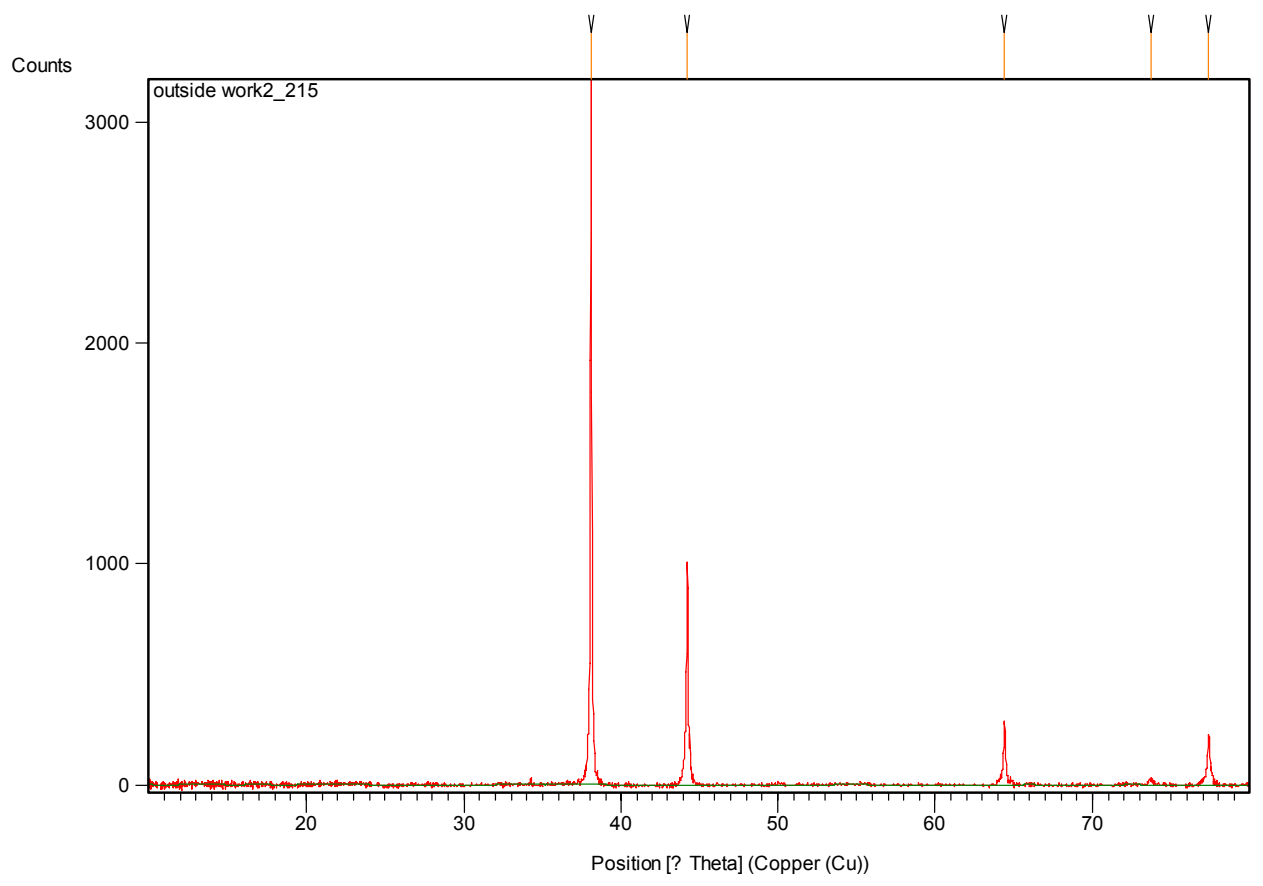

Figure 4. XRD pattern for 50\% Silver and 50\% Copper alloy for a peak current density of $3.7453 \mathrm{~A} / \mathrm{dm}^{2}$ 